\title{
NEAR-DROWNING: CORRELATION OF LEVEL OF CONSCIOUSNESS AND SURVIVAL
}

\author{
J.H. Modell, S.A. Graves and E.J. Kuck
}

ABSTRACT

\begin{abstract}
This paper reports a retrospective review of 121 cases of near-drowning treated at university hospitals in Miami and Gainesville. The series included 57 adults and 64 children who were classified into three categories, Category A (Awake), Category B (Blunted) and Category C (Comatose), based on their level of consciousness on arrival at the primary hospital.

Results based on the total 121 patients showed 87 per cent survived with apparently normal brain function, two per cent survived with impaired brain function and 11 per cent died. The survival rate of all patients who were awake when they entered the hospital was significantly greater than that of both those who were admitted with blunted consciousness $(p=0.05)$ and those who were comatose when admitted $(p<0.0001)$. Further, the group whose members had blunted consciousness had a significantly greater number of normal survivors than the group whose members were comatose on admission ( $p<0.002$ ).

All treated adults survived without permanent neurological damage and only three surviving children in the series suffered residual brain damage. Whether the course of the seven patients, three adults and four children, who died without return of brain function, would have been altered by deliberate attempts to preserve the brain is a matter of speculation.
\end{abstract}

DURING THE PAST FEW YEARS, some reports have emphasized the incidence of severe neurological sequelae after near-drowning. ${ }^{1,2}$ The reported incidence of persons who survive a near-drowning episode but suffer incapacitating brain damage varies from 0 to 21 per cent. ${ }^{\text {t-5 }}$ At least one author' reporting a high incidence of brain damage questions whether all near-drowning victims should be resuscitated; others have intraduced intensive therapy aimed primarily at brain preservation. ${ }^{2}$

To identify which patients are most susceptible to residual brain damage or death after neardrowning and therefore, perhaps, to give guidance to the clinician, we developed, in conjunction with Dr. Alan Conn of Toronto, a method of categorizing near-drowning victims

\section{MethodS}

The charts of 121 patients treated for neardrowning between 1963 and 1979 at the University of Miami School of Medicine and the University of Florida College of Medicine were reviewed retrospectively.* Since information obtained from persons who were at the scene of the

J.H. Modell, M.D., S.A. Graves, M.D., and E.J. Kuck, Departments of Anesthesiology and Pediatrics, University of Florida College of Medicine, Box J-254, J. Hillis Miller Health Center, Gainesville, Florida 32610 , U.S.A.

Reprint requests to J.H. Modell, M.D.

*University of Miami, July 1963-July 1973; University of Florida, July 1969-October 1979. Ninety-one of these patients have been reported previously. ${ }^{4}$ accident was notoriously unreliable in regard to duration of submersion and exact details of resuscitation, we elected to categorize our patients according to their levels of consciousness, recorded when they reached the emergency room of the first hospital to receive them. The categories follow:

Group $A$ (awake). These patients were described as awake and oriented when they reached the emergency room. Many of these patients had received cardiopulmonary resuscitation at the scene of the accident because of apnoea and suspected cardiac arrest

Group $B$ (blunted). These patients suffered from what we have termed a blunted consciousness, indentified by such descriptions as lethargic, semi-comatose, combative, agitated, disoriented, and confused.

Group $C$ (comatose). These patients were described as comatose at the time they arrived at the hospital.

In no case were attempts made to treat any patient pharmacologically for brain insult. In general, therapy centered around intensive pulmonary care, cardiovascular support, and fluid replacement as required. ${ }^{4,6,7}$

Groups A, B and C were compared with each other, as were the adults and children in each group, by the Fisher exact test.

\section{RESULTS}

Group A. Sixty-one patients, 27 adults (age $34.7 \pm 2.9$ years) and 34 children (age $6.5 \pm 0.8$

Canad. Anaesth. Soc. J., vol. 27, no. 3, May 1980 
TABLE I

Outcome of Near-Drowned Adults and Children According to Their Level of Consciousness When ADMITTED TO THE EMERGENCY ROOM

\begin{tabular}{|c|c|c|c|c|c|c|c|c|c|c|c|c|c|c|c|c|c|c|}
\hline \multirow{3}{*}{$\begin{array}{l}\quad \text { Level of } \\
\text { consciousness } \\
\text { on admission }\end{array}$} & \multicolumn{6}{|c|}{ Adults } & \multicolumn{6}{|c|}{ Children } & \multicolumn{6}{|c|}{ Total } \\
\hline & \multicolumn{2}{|c|}{$\begin{array}{l}\text { Normal } \\
\text { Survival }\end{array}$} & \multicolumn{2}{|c|}{$\begin{array}{c}\text { Severe } \\
\text { Brain } \\
\text { Deficit }\end{array}$} & \multicolumn{2}{|c|}{ Death } & \multicolumn{2}{|c|}{$\begin{array}{l}\text { Normal } \\
\text { Surviva! }\end{array}$} & \multicolumn{2}{|c|}{$\begin{array}{l}\text { Severe } \\
\text { Brain } \\
\text { Deficit }\end{array}$} & \multicolumn{2}{|c|}{ Death } & \multicolumn{2}{|c|}{$\begin{array}{l}\text { Normal } \\
\text { Survival }\end{array}$} & \multicolumn{2}{|c|}{$\begin{array}{l}\text { Severe } \\
\text { Brain } \\
\text { Deficit }\end{array}$} & \multicolumn{2}{|c|}{ Death } \\
\hline & $\mathrm{n}$ & $\%$ & $\pi$ & $\%$ & $n$ & $\%$ & $\mathrm{n}$ & $\%$ & $n$ & $\%$ & $\mathrm{n}$ & $\%$ & $n$ & $\%$ & n & $\%$ & $\mathrm{n}$ & $\%$ \\
\hline Awake & 27 & 100 & 0 & 0 & 0 & 0 & 34 & 100 & 0 & 0 & 0 & 0 & 61 & 100 & 0 & 0 & 0 & 0 \\
\hline Blunted & 17 & 89 & 0 & 0 & 2 & 11 & 11 & 92 & 0 & 0 & 1 & 8 & 28 & 90 & 0 & 0 & $\mathbf{3}$ & 10 \\
\hline Comatose & 8 & 73 & 0 & 0 & 3 & 27 & 8 & 44 & 3 & 17 & 7 & 39 & 16 & 55 & 3 & 10 & 10 & 34 \\
\hline Total & 52 & 91 & 0 & 0 & 5 & 9 & 53 & 83 & 3 & 5 & 8 & 13 & 105 & 87 & 3 & 2 & [3] & 11 \\
\hline
\end{tabular}

years, mean \pm SEM), were awake and oriented when admitted to the emergency room. All of these patients survived with normal brain function, as assessed by clinical examination and comparison of the level of the individual's activity before and after the accident (Table I).

Group B. Nineteen adults (age $31.5 \pm 3.9$ years) and 12 children (age $5.6 \pm 1.2$ years) were described as having a blunted consciousness when admitted to the emergency room. Seventeen of the adults ( 89 per cent) and 11 of the children ( 92 per cent) made completely uneventful recoveries without residual neurological deficit (Table I). Two adults and one child died; these three patients deserve special mention. Both adults were scuba diving when their accidents occurred - one at 70 feet below the surface, the other at 60 feet. Both patients required cardiopulmonary resuscitation at the scene of the accident and on admission to the hospital were thought to have suffered hyperbarism as well as severe pulmonary aspiration. The lack of a hyperbaric chamber of sufficient size and sophistication to permit intensive care precluded recompression of the two divers. Each had extensive subcutaneous emphysema and bilateral pneumothoraces, which prevented effective application of high levels of positive end-expiratory pressure. Both divers subsequently died of severe pulmonary insufficiency. The mental status of these patients appeared appropriate before they died. The death of the child occurred very early in the study, when the importance of intensive pulmonary therapy was poorly appreciated and before positive end-expiratory pressure therapy was introduced. This child was treated ultraconservatively with an oxygen tent and, since equipment for evaluation of arterial blood gas tensions was not readily available in that hospital at the time, measurements of blood gases were not obtained until immediately before the child died. The arterial oxygen tension was found to be $2.66 \mathrm{kPa}$ ( 20 torr) and the child died while the sample was being analyzed.

Group C. Twenty-nine patients were comatose on arrival at the hospital. Of the 11 adults (age $37.9 \pm 4.6$ years), eight ( 73 per cent) survived with apparently normal brain function and three patients died. The 18 children (age $6.6 \pm 1.2$ years) were not as fortunate; only eight ( 44 per cent) survived with apparently normal brain function, seven ( 39 per cent) died and three (17 per cent) lived with incapacitating brain damage (Table I). While these figures suggest that the normal survival rate may be lower for children than for adults, the difference between them is not statistically significant $(p=0.1)$. Of the ten patients who died, seven (three adults and four children) never regained consciousness; the remaining three died of severe pulmonary insufficiency.

\section{Statistical Comparison of The Groups}

When the adults were analyzed separately, the percentages of survivors with normal brain function in Group A and in Group B did not differ statistically $(p>0.15)$. Likewise, the percentages of survivors in Group B and in Group $C$ did not differ $(p=0.2)$. However, when the percentage of adult survivors who were awake when admitted to the hospital was compared to the percentage of normal survivors who were comatose when they entered the hospital, the survival rate of Group $A$ is significantly greater than that of Group C $(p<0.02)$.

When the children were analyzed separately. the survival rates of Groups A and B did not differ ( $p>0.25$ ). However, the percentages of normal survivors were significantly greater both in Group A and in Group B than in Group $C(p<0.001)$.

When adults and children were combined, of 
the 121 total patients treated, 87 per cent survived with apparently normal brain function, two per cent survived with impaired brain function and 11 per cent died (Table I). The survival rate of all patients who were awake when they entered the hospital was significantly greater than that of both those who were admitted with blunted consciousness $(p=0.05)$ and those who were comatose when admitted $(p<0.0001)$. Further, the group whose members had blunted consciousness had a significantly greater number of normal survivors than the group whose members were comatose on admission $(p<0.002)$.

\section{Discussion}

The recent literature varies from extremely optimistic to pessimistic regarding the outcome of normal brain function for patients resuscitated after near-drowning. ${ }^{1,3}$ Also, some persons advocate aggressive attempts to preserve brain function. ${ }^{2}$ Therefore, we fict that a review of our data was important to seek factors that might help us to predict which patients would survive normally with intensive therapy aimed primarily at pulmonary and cardiovascular support.

In interviewing first responders, we frequently found extreme disparity in the history reported when more than one rescuer was involved. Thus, the duration of submersion reported by the rescuer may be unreliable. Some persons have suggested that long submersion times in warm water are not compatible with return of satisfactory brain function. Interestingly, one of our patients was submerged in a freshwater pool for ten minutes by the clock. She initially was resuscitated with cardiopulmonary resuscitation and approximately 24 hours later was able to respond appropriately to spoken commands and to communicate on paper (vocal communication was not possible because of tracheal intubation). Unfortunately, 84 hours later, that patient (Group C) died of extensive pulmonary destruction.

Likewise, we have not found the initial measurements of arterial $\mathrm{pH}$ and blood gas tensions to be of absolute prognostic value. We have treated a patient with a pHa of 6.90 on admission and another with a $\mathrm{Pa}_{\mathrm{O}_{2}}$ of $2.26 \mathrm{kPa}$ (17 torr) while being mechanically ventilated with 100 per cent oxygen, and both survived with normal brain function. On the other hand, one patient with an initial pHa of 7.43 and $a \mathrm{~Pa}_{\mathrm{O}_{2}}$ of $12 \mathrm{kPa}$ ( 90 torr) $\left(\mathrm{FI}_{\mathrm{O}_{2}} 0.3\right.$ ) suffered permanent brain damage and another patient with an initial $\mathrm{pHa}$ of 7.41 died.

We have reported previously that all patients in our 1976 series who had fixed dilated pupils on admission to the emergency room died. ${ }^{4}$ Since that time we have treated a patient who was comatose, with fixed dilated pupils when admitted to the hospital, but who made a normal recovery.

Since 100 per cent of our patients who ivere awake and 90 per cent of those who had blunted consciousness when they reached the emergency room survived with normal brain function, and since the three in Group B who died were pulmonary deaths, we believe that patients in categories $A$ and $B$ should be treated with intensive pulmonary and cardiovascular support, but that techniques for brain protection such as barbiturateinduced coma and hypothermia are unnecessary and may increase the hazards to the patient.

In our previous report we suggested that the use of steroids and prophylactic antibiotics does not improve the survival rate. ${ }^{4}$ Our subsequent experience with the last 30 cases in which these drugs were not used after the patients arrived at our hospital substantiates that previous suggestion. Further, since that time Wynne et al. ${ }^{8}$ have demonstrated that the use of corticosteroids after aspiration of food-stuff may actually hinder normal pulmonary healing. Therefore, we can comfortably state that steroids are not indicated for patients in Groups A and B. Some clinicians might argue with this conclusion for patients with blunted consciousness; however, since none of our patients with blunted consciousness suffered nęurological damage, we believe that withholding steroids from this group is justified.

The patients who are comatose when they enter the hospital present a more complicated picture. None of our patients have been treated with barbiturate-induced coma or deliberate hypothermia in an attempt to preserve brain function. Many of these patients, however, have been deliberately hyperventilated to produce respiratory alkalosis and thus to decrease cerebral blood flow and, potentially, to decrease cerebral oedema. Also, many have been treated with corticosteroids, since some persons think these drugs are helpful in such situations, 9 Though we did not use methods such as barbiturate coma to preserve brain function, all adults we treated survived without permanent neurological damage and only three surviving children in our series suffered residual brain damage. Whether the course of the seven patients (three adults and four children) who died without return of normal brain function would have been altered by deliberate attempts to preserve the brain is a matter of speculation. A similar study was done by Conn et 
al. ${ }^{10}$ in Toronto where H.Y.P.E.R. therapy aimed at brain preservation was used for 26 of 39 patients. When one compares the children in Group C of our study with those of Conn's work, the overall data for survival, deaths, and residual brain damage are virtually identical in both series. ${ }^{10}$ This leads one to question whether such therapy is necessary. We believe that there may be some differences between these two series that are not apparent from the statistics alone. Conn et al. were able to divide their patients in Category $\mathrm{C}$ into three sub-groups, but we were unable to do this retrospectively. Since their survival data in sub-groups C. 1 (decorticate) and C.2 (decerebrate) were significantly better than in sub-group C.3 (flaccid), it is possible that the distribution of patients may have been different in the two series. Thus we cannot be precise in our comparisons of normal survival rates with and without H.Y.P.E.R. therapy between these institutions. If the case distribution between subgroups is identical in the two series it would suggest that H.Y.P.E.R. therapy is unnecessary. If one series were skewed regarding the number of patients in sub-groups C. I, C.2 or C.3, completely different conclusions might be reached. This suggests the need for an inter-institutional prospective study in comparable circumstances.

It should be noted that if we treat one additional adult and one child in Group $C$, and if the adult lives and child dies or is brain damaged, the percentages of normal survivals between these two groups would differ significantly at the $p=0.05$ level. This difference would then require an explanation. One consideration is that the heart of the child might be resuscitated after much longer periods of arrest and hypoxia than that of the adult. However, the child's brain may not tolerate cerebral hypoxia for the same length of time. This possibility may be important when one compares drowning statistics between institutions. It is important to ensure that the age of patients, the caliber of emergency medical services available at the scene of the accident and the ability of the institution to provide intensive care are similar if comparisons of survival statistics are to be valid.

We believe that the quality of the initial resus- citative therapy administered at the scene of the accident is paramount to the ultimate outcome of the near-drowned victim. Patients whose level of consciousness is either awake or blunted when admitted to the hospital should be treated with intensive pulmonary and cardiovascular support but, since these patients do not suffer brain damage, extraordinary attempts at brain preservation are unnecessary. The need for intensive therapy aimed at brain preservation for patients who are still comatose when admitted to the hospital requires further study.

\section{ACKNOWLEDGEMENTS}

The authors thank B.C. Ruiz, N. Davis and L. Carroll for their assistance in the preparation of this manuscript.

\section{REFERENCES}

1. Petersen, B. Morbidity of childhood neardrowning. Pediatrics 59: 364-370 (1977).

2. Conn, A. W., Edmonds, J.F. \& Barker, G.A Near-drowning in cold fresh water: current treatment regimen. Canad. Anaesth. Soc. J. 25: 259-265 (1978).

3. Pearn, J.H., Bart, R.D., JR. \& Yamaoka, R. Neurologic sequelae after childhood neardrowning: a total population study from Hawaii. Pediatrics 64: 187-191 (1979).

4. Modell, J.H., Graves, S.A. \& Ketover, A. Clinical course of 91 consecutive near-drowning victims. Chest 70: 23I-238 (1976).

5. Pearn, J.h., Nixon, J. \& Wilkey. I. Freshwater drowning and near-drowning accidents involving children: a five-year total population study. Med. Journal of Australia 2: 942-946 (1976).

6. MoDELL, J.H. Drowning and near-drowning, in disorders of the respiratory tract in children. Eds. Kendig, E.L., Jr. and Chernik, V., Saunders (1977) pp. $498-510$.

7. Modell, J.H. Biology of drowning. Ann. Rev. Med. 29: 1-8 (1978).

8. Wrnne, J.W., Reynolds, J.C., Hood, C.I., AuERBACH, D. \& ONDRASICK, J. Steroid therapy for pneumonitis induced in rabbits by aspiration of foodstuff. Anesthesiology 51: 11-19 (1979).

9. Fishms , R.A. Brain edema. New Engl. J. Med. 293: 706-711 (1975).

10. Conn, A.W., Montes, J.E., Barker, G.A. \& EDMONDS, J.F., Cerebral salvage in neardrowning following neurological classification by triage. Can. Anaes. Soc. Jour. 27: 20l-209 (1980).

\section{RÉSUMÉ}

Les auteurs ont revu les dossiers de 121 patients traités dans les hôpitaux universitaires de Miami et de Gainesville après avoir survécu à la noyade. Les 57 adultes et les 64 enfants que comprenait cette série ont été classifiés en trois groupes selon leur état de conscience à l'arrivée à la salle d'urgence. Un premier groupe comprenait les 61 patients qui étaient 
conscients et orientés à l'arrivée. Un second groupe était formé des 31 patients décrits à l'arrivée comme obnubilés (semi-comateux, confus, agités), alors que les 29 malades admis en coma ont été groupés dans un troisième groupe.

Quatre-vingt-sept pour cent des patients ont survécu sans séquelles neurologiques, 2 pour cent avec atteinte neurologique et 11 pour cent des patients sont décédés. Le taux de survie de ceux qui étaient conscients a l'arrivée était significativement plus élevé que celui des patients obnubilés ou comateux. De même, le taux de survie s'est avéré plus élevé chez les malades obnubilés à l'arrivée que chez ceux qui étaient en coma.

Aucun des adultes survivants n'a présenté de complications neurologiques alors que trois survivants chez les enfants ont présenté des séquelles neurologiques permanentes. L'évolution des sept adultes et des quatre enfants décédés sans amélioration de l'activité cérẻbrale aurait-elle pu être modifiéc par des techniques de protection cérébrale? Les auteurs ne peuvent répondre à cette question à partir de leur série. 